\title{
Fulvestrant up regulates UGT1A4 and MRPs through ERa and c-Myb pathways: a possible primary drug disposition mechanism
}

\author{
Vineetha K Edavana ${ }^{1}$, Rosalind B Penney ${ }^{2}$, Aiwei Yao-Borengasser ${ }^{1}$, Suzanne Williams ${ }^{1}$, Lora Rogers ${ }^{1}$, \\ Ishwori B Dhakal ${ }^{1}$ and Susan Kadlubar ${ }^{{ }^{*}}$
}

\begin{abstract}
Fulvestrant (Faslodex ${ }^{\mathrm{TM}}$ ) is a pure antiestrogen that is effective in treating estrogen receptor-(ER) positive breast cancer tumors that are resistant to selective estrogen receptor modulators such as tamoxifen. Clinical trials investigating the utility of adding fulvestrant to other therapeutics have not been shown to affect cytochrome P450-mediated metabolism. Effects on phase II metabolism and drug resistance have not been explored. This study demonstrates that fulvestrant up regulates the expression of UDP glucuronosyltransferase 1A4 (UGT1A4) $>2.5$ and $>3.5$-fold in MCF7 and HepG2 cells, respectively. Up regulation occurred in a time- and concentration-dependent manner, and was inhibited by siRNA silencing of ERa. Fulvestrant also up regulates multidrug resistance-associated proteins (MRPs). There was an up regulation of MRP2 (1.5- and 3.5-fold), and MRP3 (5.5- and 4.5-fold) in MCF7 and HepG2 cell lines, respectively, and an up regulation of MRP1 (4-fold) in MCF7 cells. UGT1A4 mRNA up regulation was significantly correlated with UGT1A4 protein expression, anastrozole glucuronidation, ERa mRNA expression and MRP mRNA expression, but not with ERa protein expression. Genetic variants in the UGT1A4 promoter $(-163 \mathrm{~A},-217 \mathrm{G}$ and -219T) reduced the basal activity of UGTIA4 by $40-60 \%$. In silico analysis indicated that transcription factor c-Myb binding capacity may be affected by these variations. Luciferase activity assays demonstrate that silencing c-Myb abolished UGT1A4 up regulation by fulvestrant in promoters with the common genotype (-163G, $-217 \mathrm{~T}$ and -219C) in MCF7 cells. These data indicate that fulvestrant can influence the disposition of other UGT1A4 substrates. These findings suggest a clinically significant role for UGT1A4 and MRPs in drug efficacy.
\end{abstract}

Keywords: Fulvestrant; Anastrozole; UGT1A4; MRPs; ERa; c-Myb

\section{Introduction}

Fulvestrant (Faslodex ${ }^{\mathrm{m}}$; ICI 182,780) belongs to a novel class of endocrine agents for the treatment of breast cancer (Howell et al. 2000; Osborne et al. 2004). Fulvestrant is a pure antiestrogen which is effective in treating estrogen receptor (ER) positive tumors that are resistant to selective estrogen receptor modulators (SERMs) such as tamoxifen This compound differs significantly from tamoxifen in its mode of action, which is through promoting the rapid degradation of the ER. Fulvestrant shows no estrogen agonist activity, and thus has been regarded as an important improvement in breast cancer therapy (Morris and Wakeling

\footnotetext{
* Correspondence: sakadlubar@uams.edu

${ }^{1}$ Division of Medical Genetics, College of Medicine, University of Arkansas for Medical Sciences, 4301 W. Markham, \#580, Little Rock, AR, 72205, USA Full list of author information is available at the end of the article
}

2002; Howell et al. 2002; Osborne et al. 2002). It is thought that co-administration of fulvestrant with other therapeutics may be beneficial, and clinical trials investigating this are being conducted (Group 2004; AstraZeneca 2012). However, the effect of co-administration on phase II drug metabolism and drug disposition has not yet been reported.

The phase II biotransformation system comprises an array of enzymes that incorporate a hydrophilic group into hydrophobic molecules, thereby increasing solubility and potentially decreasing the toxicity of the original target. Altered rates of metabolism can affect systemic availability and elimination half-life of xenobiotics. This can affect toxicity or therapeutic effect, and may result in undesirable drug-drug interactions. A better understanding of simultaneous regulation of metabolism and disposition may help prevent these undesirable effects.

\section{实}


Fulvestrant is primarily metabolized by cytochrome P450 enzymes (CYPs) and phase II enzymes like sulfotransferases (SULTs) and UDP-glucuronosyltransferases (UGTs). Fulvestrant has been shown to be glucuronidated by human recombinant UGT1A1, UGT1A3, UGT1A4 and UGT1A8 enzymes. Kinetic analysis has revealed that UGT1A4 displays the highest affinity for fulvestrant, and that UGT1A3 and UGT1A4 display the highest catalytic efficiency for fulvestrant glucuronidation (Chouinard et al. 2006; Starlard-Davenport et al. 2010).

Previous studies from this laboratory report that genetic variations in UGT1A4 have a potential role in inter-individual variability in anastrozole glucuronidation (Edavana et al. 2013). These findings indicate that alterations in UGT1A4 may significantly affect the glucuronidation rates of fulvestrant. Thus variations may also affect metabolism and disposition of drugs that are coadministered with fulvestrant and which are substrates for UGT1A4.

Drug disposition can be affected not only by factors such as metabolic genes, but also transporter proteins (Bock et al. 2000; Catania et al. 2004). Multidrug resistance-associated proteins (MRPs) are a family of ATP-dependent transporters that exhibit elevated expression levels in tumor cells. MRPs are preferentially localized in the apical membrane of hepatocytes, renal tubular cells and enterocytes (Catania et al. 2004). They are involved in the secretion of a large number of conjugated compounds, and most MRP substrates are conjugated derivatives of endogenous compounds, drugs and carcinogens (Keppler et al. 1997). Thus, MRPs may act coordinately with phase II enzymes to eliminate these compounds from the body. In the present study, the effects of fulvestrant on phase II metabolism regulation, drug disposition and interactions with other therapeutics are explored in breast cancer and liver cancer cell lines.

\section{Materials and methods Chemicals and reagents}

Fulvestrant was provided by AstraZeneca Pharmaceuticals (Macclesfield, Cheshire, UK). Anastrozole (2,2' - [5-(1H-1,2,4triazol-1-ylmethyl)-1,3-phenylene]bis (2-methylpropanenitrile) was obtained from Toronto Research Chemicals, Inc. (Toronto, Canada). Alamethicin and UDP glucuronic acid (UDPGA) were purchased from Sigma-Aldrich (St. Louis, MO). Baculovirus-expressed human UGT1A4 was purchased from BD Gentest Corp. (Woburn, MA). ER $\alpha$ siRNA (h), $c-M y b$ siRNA (h), ER $\alpha, c-M y b$ and UGT1A4 primary and secondary antibodies were purchased from Santa Cruz Biotechnology, Inc. (Santa Cruz, CA). Actin primary antibody was purchased from Sigma-Aldrich (St. Louis, MO) Chemiluminescence reagents were obtained from GE Healthcare (Piscataway, NJ). All other reagents were of HPLC grade or of the highest grade commercially available.

\section{Cell culture}

MCF7 cells from American Type Culture Collection were maintained in RPMI 1640 supplemented with 10\% fetal bovine serum, $2 \mathrm{mM}$ L-glutamine, $6 \mathrm{ng}$ of bovine insulin/ml, 100 units of penicillin/ml, $100 \mu \mathrm{g}$ of strepto$\mathrm{mycin} / \mathrm{ml}$, and $1 \%$ minimal essential medium nonessential amino acids. HepG2 cells (a kind gift from Yevgeniy Apostolov, UAMS, AR) were cultured in complete Dulbecco's modified Eagle's medium (MediaTech, Inc., Manassas, VA) supplemented with $10 \%$ fetal bovine serum (Gemini, Woodland, CA), 2 mM L-glutamine, 100 units of penicillin $/ \mathrm{ml}, 100 \mu \mathrm{g}$ of streptomycin $/ \mathrm{ml}$, and $1 \%$ minimal essential medium nonessential amino acids. The media were changed 3 days before each experiment to estrogen-free media, i.e. complete Dulbecco's modified Eagle's medium containing charcoal/dextran-stripped fetal bovine serum (Gemini) and no phenol red.

\section{Transfection of ERa and c-Myb siRNA}

$E R \alpha$ and $c-M y b$ siRNAs were transfected into cells according to manufacturer's protocol. The final concentration of inhibitor was $100 \mathrm{nM}$. After $48 \mathrm{~h}$, cells were harvested, total RNA was isolated, and $E R \alpha$ and $c-M y b$ expressions were measured by RT-PCR according to manufacturer's protocol (see below).

\section{Quantitative real-time PCR}

Total RNA was isolated using TRIzol (Invitrogen, Carlsbad, CA), and was used as a template for cDNA synthesis with Superscript II (Invitrogen, Grand Island, NY). Quantitative RT-PCR was performed using a Prism 7900HT Sequence Detection System and SYBR Green PCR Master Mix (Applied Biosystems, Foster City, CA). Gene specific primers, annealing temperature and cycle numbers for UGT1A4, ER $\alpha, M R P 1, M R P 2$ and $M R P 3$ have been described previously (Edavana et al. 2013; Ros et al. 2003; Walton et al. 2009). The dissociation curves for each reaction were examined to ensure amplification of a single PCR product in the reaction. The -fold change in mRNA levels was determined after normalizing the gene expression levels to those of $\beta$-actin $\left(2^{-\Delta \Delta \mathrm{Ct}}\right.$ method) as described previously (Schmittgen and Livak 2008). Taqman gene expression assay (ABI, Foster city, CA) was performed to assess $c-M y b$ expression.

\section{Transient transfection of UGT1A4 promoter constructs and luciferase activity assay}

A UGT1A4 promoter construct of $1.5 \mathrm{~kb}$ was inserted upstream of the luciferase reporter gene in the pLightSwitch_Prom vector (SwitchGear Genomics, Menlo Park, CA). Variant alleles were generated with the QuikChange $^{\oplus}$ Site-Directed Mutagenesis Kit (Stratagene, La Jolla, CA). Transient transfections of reference and variant promoter constructs (100 ng) were performed 
according to manufacturer's protocol using Fugene HD (Promega, Sunnyvale, CA). After $24 \mathrm{hrs}$ cells were treated either with fulvestrant $(10 \mathrm{nM})$ or ethanol (vehicle, $0.1 \%$ ) for 48 hours. Luciferase activity was assessed with the LightSwitch Luciferase assay system (SwitchGear Genomics) following the manufacturer's protocol. Results were analyzed by normalizing luciferase in transfected cells to cells transfected with the empty pLightSwitch_Prom vector. To determine the effect of transcription factor $c-M y b$ on UGT1A4 promoter expression, MCF7 cells transfected with the variant promoter construct were treated with $c-M y b$ siRNA before fulvestrant treatment, and luciferase activity was assessed.

\section{Preparation of cytosol microsomes from cell lines}

Solubilized microsomal protein was prepared as described previously (Sirois et al. 1992; Muller-Decker et al. 1995) with minor modification. Briefly, subconfluent growth-arrested cells were homogenized on ice in Tris-EDTA-diethyldithiocarbamic (TED) buffer [50 mM Tris HCI (pH 8.0), $10 \mathrm{mM}$ EDTA, and $1 \mathrm{mM}$ diethyldithiocarbamic acid] containing $2 \mathrm{mM}$ octyl glucoside. Cells were then centrifuged at $100,000 \times \mathrm{g}$ for $1 \mathrm{~h}$ at $4^{\circ} \mathrm{C}$. The crude pellets were sonicated in TED sonication buffer [20 msi; Tris-HCI (pH 8.0), 50 mM EDTA, and $0.1 \mathrm{mM}$ diethyldithiocarbamic acid] containing $45 \mathrm{mM}$ octyl glucoside. The sonicates were centrifuged at 13,000 $\times \mathrm{g}$ at $4^{\circ} \mathrm{C}$, and the recovered supernatants containing the cytosolic microsomes were stored at $-80^{\circ} \mathrm{C}$ until the assays were performed.

\section{Western blot}

Cell lysates were separated by $12 \%$ SDS-polyacrylamide gel electrophoresis. Proteins were transferred to a polyvinylidene fluoride membrane and probed with anti-ER $\alpha$, anti-cMyb and anti-UGT1A4 antibodies according to manufacturer's protocol. Membranes were then incubated with secondary antibody for $1 \mathrm{~h}$ before chemiluminescence detection using SuperSignal West Femto Maximum Sensitivity Substrate (Pierce, Rockford, IL). Actin was detected as a loading control. Images were collected and analyzed using the FluorChem $^{\mathrm{m}}$ SP imager with Alpha Ease FC (FluorChem $^{\text {Tм }}$ SP) software (San Leandro, CA).

\section{In silico SNP analysis}

The in silico program, is-rSNP, was utilized to explore binding capacity changes in the promoter containing variant sequences. The program utilizes JASPAR and TRANSFAC to access the position weight matrix, and uses this and a "sliding window approach" to create scores and p-values that relate to transcription factor binding capacity (Macintyre et al. 2010).

\section{Glucuronidation of anastrozole using microsomes isolated from MCF7 and HepG2 cell lines}

The glucuronidation of anastrozole was measured in microsomes prepared from MCF7 and HepG2 cell lines. Enzymatic assays were performed according to standard procedure described previously (Benoit-Biancamano et al. 2009; Kamdem et al. 2010).

\section{Statistical analysis}

Student's t-tests were used to compare baseline and treatment measurements within a group. Pearson's correlation coefficients were used to describe the linear association between variables. All data from samples were expressed as mean \pm SEM. Statistical significance was set at $\mathrm{p}<0.05$.

\section{Results}

\section{Induction of UGT1A4 expression and activity by fulvestrant}

To examine the effect of fulvestrant on the expression of UGT1A4, ER $\alpha+$ MCF7 and HepG2 cells were used. When concentration studies were performed, both cell lines showed strong sensitivity towards $10 \mathrm{nM}$ fulvestrant. Cells were pre-treated with $1 \mathrm{nM}$ fulvestrant for 30 days before experiments to decrease sensitivity and increase longevity during subsequent fulvestrant treatment. Cells were treated with different concentrations $(0,5,10,20,30$, and $50 \mathrm{nM})$ of fulvestrant for 48 hours. UGT1A4 was up regulated by fulvestrant treatment, and the expression of UGT1A4 essentially plateaus at concentrations higher than $10 \mathrm{nM}$ (Figure 1a). After treatment with $10 \mathrm{nM}$ fulvestrant, cells were harvested at different time points $(0,24,48,72$ and $96 \mathrm{hrs})$ and mRNA levels were determined by qRT-PCR. Treatment with fulvestrant up regulated UGT1A4 in a timedependent manner. Endogenous mRNA expression levels of UGT1A4 peaked at 72 hours ( $>2.5$-fold) in MCF7 cells, and at 48 hours (>3.5-fold) in HepG2 cells (Figure 1b). To determine if the regulation of UGT1A4 is mediated by the ER, siRNA silencing of $E R \alpha$ was performed before repeating these experiments, which abolished UGT1A4 up regulation upon fulvestrant treatment (Figure 1a and b).

UGT1A4 protein levels were measured by Western blot and anastrozole glucuronidation activities were measured by mass spectrometry in MCF7 and HepG2 cells with and without $E R \alpha$ siRNA transfection before treatment. Treatments were with $10 \mathrm{nM}$ fulvestrant, and data was collected over several time points. UGT1A4 mRNA was correlated with UGT1A4 protein expression $(\mathrm{r}=0.969$ (MCF7) and 0.999 (HepG2), $\mathrm{p}<0.01$ (both)) and anastrozole glucuronidation activity $(\mathrm{r}=0.875, \mathrm{p}<$ 0.05 (MCF7), $\mathrm{r}=0.961, \mathrm{p}<0.01$ (HepG2); Table 1). 

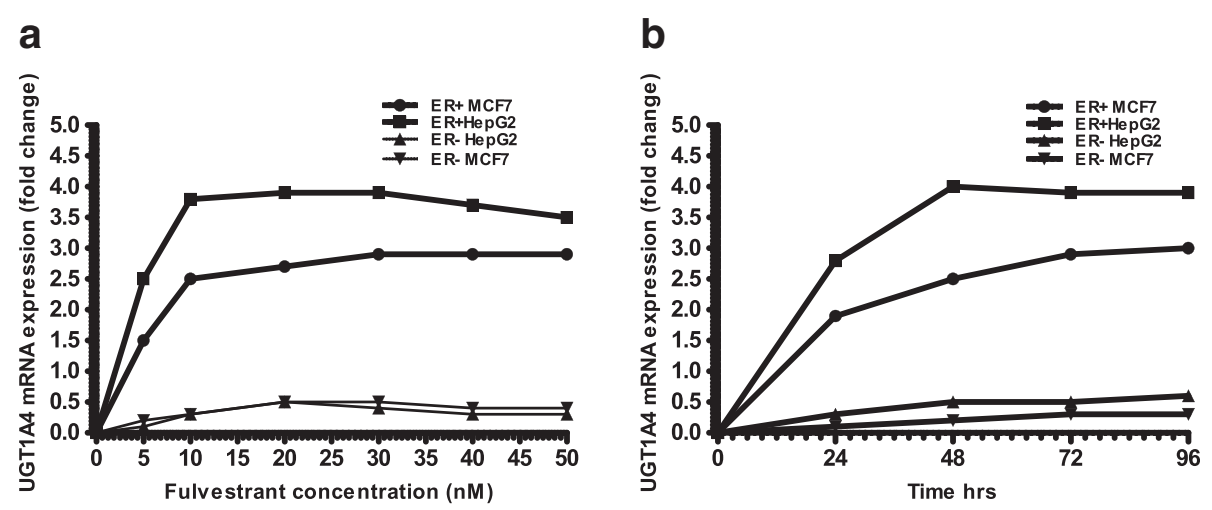

Figure 1 Up regulation of UGT1A4 mRNA expression in MCF7 and HepG2 cell lines treated with fulvestrant. (a) MCF7 and HepG2 cells \pm transfection with ERa siRNA were treated with various concentrations of fulvestrant before UGT1A4 gene expression was measured. All data was normalized to $\beta$-actin. (b) MCF7 and HepG2 cells were transfected as in (A), and then all were treated with 10 nM fulvestrant and analyzed for UGT1A4 expression at various time points.

\section{Correlation of UGT1A4 mRNA with ERa mRNA and ERa protein levels}

To confirm that UGT1A4 expression was partially mediated through the ER pathway, ER $\alpha$ mRNA and protein expression levels were measured and correlated to UGT1A4 mRNA expression levels. (Figure 2a and b) UGT1A4 mRNA expression levels correlated with ER $\alpha$ mRNA $(\mathrm{r}=0.915, \mathrm{p}<0.05$ for MCF; $\mathrm{r}=0.923, \mathrm{p}<0.01$ for HepG2), but not with ER $\alpha$ protein levels $(r=0.760$, $p>0.05$ for MCF7; $r=0.753, p>0.05$ for HepG2) in both cell lines (Table 1). These results indicate that fulvestrant induces UGT1A4 expression at least partially through an ER $\alpha$-mediated mechanism.

\section{Transcriptional activation of UGT1A4 by fulvestrant}

To study the mechanism of regulation of UGT1A4 by fulvestrant, transcriptional activity modulation by the UGT1A4 promoter was assessed by transient transfections in MCF7 and HepG2 cell lines. Each cell line was

Table 1 Correlation of UGT1A4, MRP and ERa in HepG2 and MCf7 Cell lines: Correlation analysis of MCF7/HepG2 UGT1A4 mRNA expression level with its own UGT1A4 protein, Anastrozole glucuronidation, ERa mRNA, ERa protein, MRP1, MRP2 and MRP3

\begin{tabular}{lll}
\hline & $\begin{array}{l}\text { MCF-7 } \\
\text { UGT1A4 mRNA }\end{array}$ & $\begin{array}{l}\text { HepG2- } \\
\text { UGT1A4 mRNA }\end{array}$ \\
\hline MCF7/HepG2 UGT1A4 protein & $0.969^{* *}$ & $0.999^{* *}$ \\
MCF7/HepG2 Anastrozole & $0.875^{*}$ & $0.961^{* *}$ \\
glucuronidation & & \\
MCF7/HepG2 ERa-mRNA & $0.915^{*}$ & $0.923^{* *}$ \\
MCF7/HepG2 ERa-protein & $0.760^{*}$ & 0.753 \\
MCF7/HepG2 MRP1 & $0.972^{* *}$ & NA \\
MCF7/HepG2 MRP2 & $0.906^{*}$ & $0.948^{* *}$ \\
MCF7/HepG2 MRP3 & $0.983^{* *}$ & $0.967^{* *}$ \\
\hline
\end{tabular}

** $p<0.01 ;{ }^{*} p<0.05$. transfected with either pLightSwitch-UGT1A4 or the empty pLightSwitch_Prom vector. The transfected cells were then treated either with fulvestrant or with the ethanol vehicle, and luciferase activities were determined. Upon treatment with fulvestrant, MCF7 and HepG2 cells transfected with pLightSwitch_UGT1A4 exhibited $>5$-fold $(\mathrm{p}<0.01)$ increase in luciferase activity compared with empty promoter-treated cells (Figure 3).

According to previous reports by this lab, UGT1A4 promoter SNPs $-163 \mathrm{G}>\mathrm{A},-217 \mathrm{~T}>\mathrm{G}$ and $-219 \mathrm{C}>\mathrm{T}$ have been associated with inter-individual variability in enzymatic activity in human liver microsomes (Edavana et al. 2013). In this study, similar results were seen with fulvestrant treatment. The $-163 \mathrm{G}>\mathrm{A}$ variant or the $-219 \mathrm{C}>\mathrm{T}$ variant in either or both alleles reduced the basal luciferase activity by $40-50 \%(\mathrm{p}<0.01)$ and $30-40 \%(\mathrm{p} \leq 0.01)$ respectively in MCF7 and HepG2cells. The $-217 \mathrm{~T}>\mathrm{G}$ variant in either or both alleles increased the basal luciferase expression by $20-50 \%(\mathrm{p} \leq 0.01)$ in both cell lines. The complete variant haplotype $(-163 \mathrm{~A},-217 \mathrm{G}$ and $-219 \mathrm{~T})$ reduced control luciferase activity by $40-60 \%(\mathrm{p} \leq 0.01)$ from the reference promoter in both cell lines (Figure 4).

In silico analysis using is-rSNP revealed that the UGT1A4 -163 variant is associated with changes in the $c-M y b$ transcription factor binding site. MCF7 expresses $c-M y b$, but HepG2 cells do not, therefore $c-M y b$ transcription factor silencing was performed only in MCF7 cells. In the presence of $c-M y b$, fulvestrant up-regulated the luciferase activity of UGT1A4 promoter expressing the common alleles 1.5-fold more than the promoter with the variant alleles $(\mathrm{p}<0.01$, Figure 5$)$. When $c-M y b$ was silenced, no fulvestrant-induced up-regulation in luciferase activity was detected (Figure 5). $c-M y b$ appears to affect fulvestrant-induced UGT1A4 promoter activity in the promoter with common alleles, but variation in 

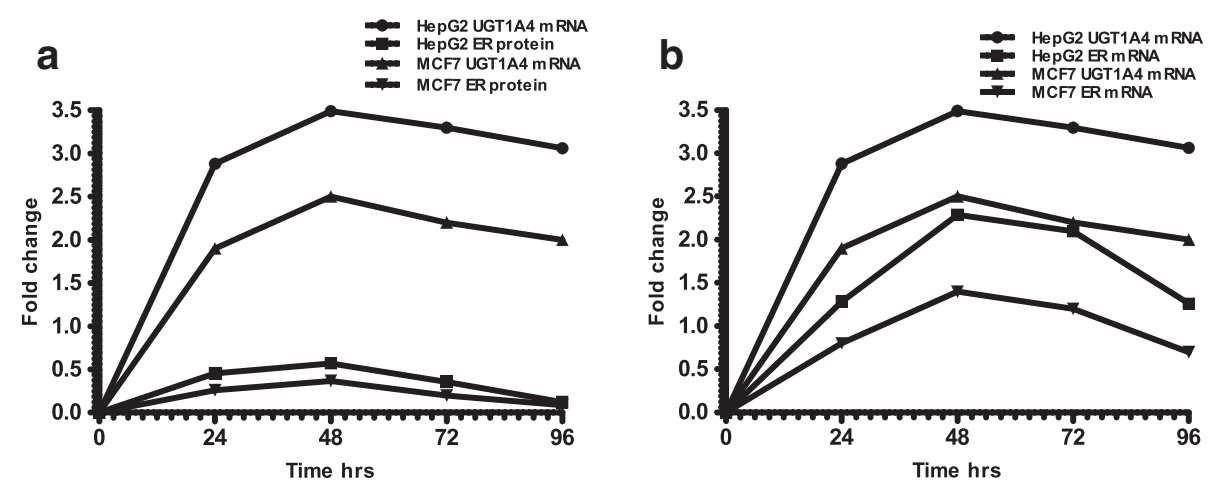

Figure 2 Correlation of UGT1A4 mRNA with ER expression. Correlation of UGT1A4 mRNA with ER protein (a) and with ER mRNA (b) in HepG2 and MCF7 cell lines treated with fulvestrant. Cells were treated with $10 \mathrm{nM}$ fulvestrant. UGT1A4 and ER mRNA and protein expressions were measured at various time points.

the UGT1A4 promoter inhibits activity and the effect of $c-M y b$ binding.

\section{Induction of multidrug resistance-associated protein by fulvestrant}

MRPs have been characterized as apical glucuronide export pumps. (Cui et al. 1999; Munzel et al. 1999). In order to investigate regulation by fulvestrant, MRP expression levels were analyzed in MCF7 and HepG2 cell lines. Cells were treated with $10 \mathrm{nM}$ fulvestrant, and $M R P 1, M R P 2$ and MRP3 expression levels were measured at various time points. Gene expression was upregulated for $M R P 1, M R P 2$ and $M R P 3$, and expression peaked at 48 hours in both cell lines. Thus, MRPs and UGT1A4 were coordinately induced by fulvestrant. UGT1A4 mRNA levels correlate with MRP1 $(\mathrm{r}=0.972$; $\mathrm{p}<0.05), M R P 2(\mathrm{r}=0.906 ; \mathrm{p}<0.01)$ and $M R P 3(\mathrm{r}=0.983$; $\mathrm{p}<0.05)$ expression levels in MCF7 cells. UGT1A4 mRNA levels correlate with MRP2 $(\mathrm{r}=0.948 ; \mathrm{p}<0.05)$ and MRP3 $(\mathrm{r}=0.967 ; \mathrm{p}<0.05)$ expression in HepG2 cells (MRP1is not expressed in HepG2; Table 1).

\section{Discussion}

Fulvestrant is effective in treating tamoxifen resistant ER-positive metastatic breast cancer tumors (Robertson et al. 2001). Recently, clinical trials investigating the utility of adding fulvestrant to other therapeutics have not been shown to affect cytochrome P450-mediated metabolism of either of the applied drugs (Robertson et al. 2004; Hiscox et al. 2009). Effects of co-administration on phase II metabolism and drug transporter genes, however, have not been explored. Metabolic biotransformation of endogenous and exogenous compounds renders lipophilic molecules more soluble in water, allowing

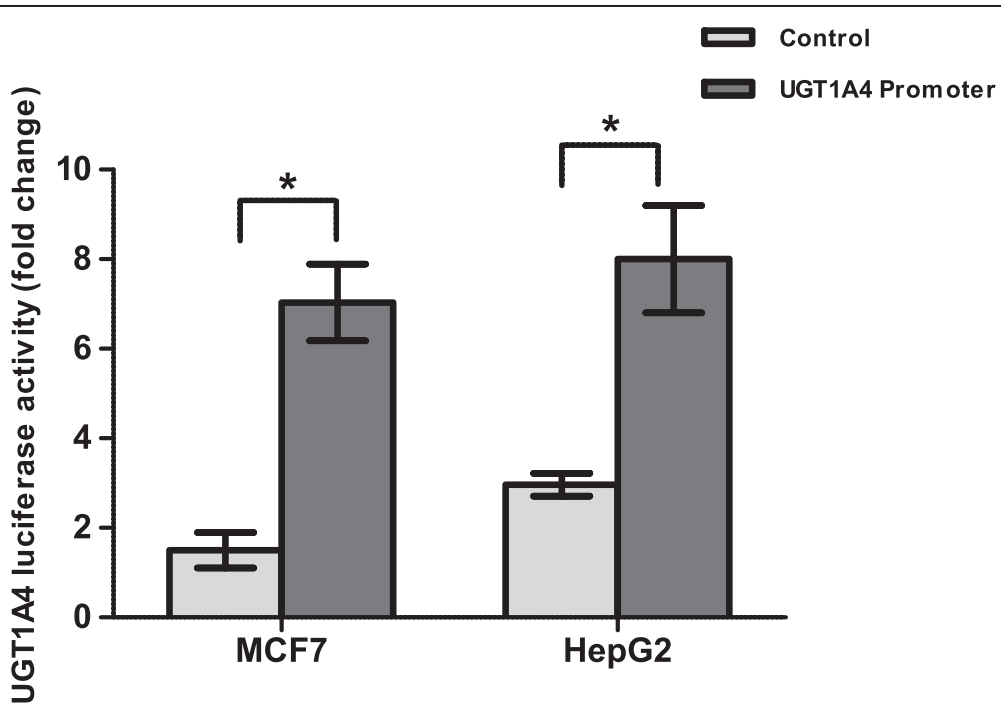

Figure 3 UGT1A4 luciferase activity measured in MCF7 and HepG2 cell lines. Cells were transfected either with empty vector or UGT1A4 reference promoter. Then treated with $10 \mathrm{mM}$ fulvestrant and luciferase activity was measured * $p$ value $<0.01$. 
a

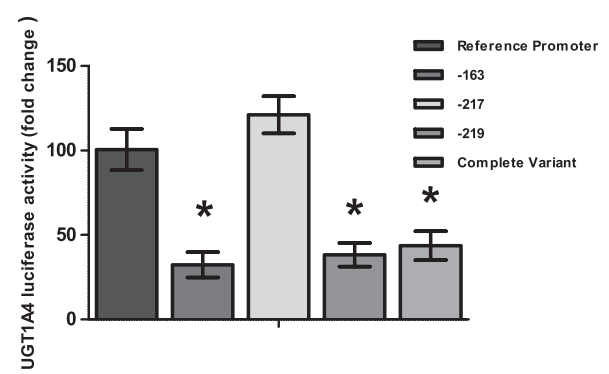

b

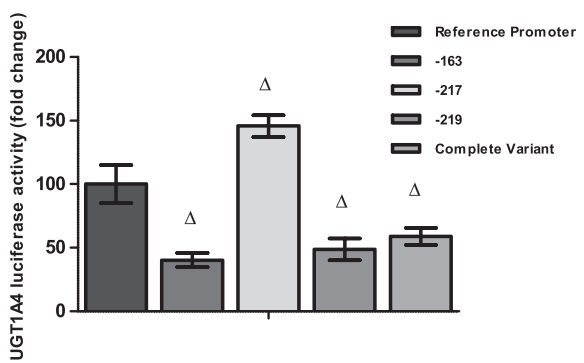

Figure 4 Promoter variant luciferase activity in various cell lines. Promoter variant luciferase activity measured in MCF7 (a) and HepG2 (b) cells. Cells were transfected either with UGT1A4 common allele promoter or with promoters with single variants at $-163,-217$, and -219 and with a promoter with all three variant (complete variant). Cells were then treated with $10 \mathrm{mM}$ fulvestrant and luciferase activity was measured, and is displayed as percentage difference ${ }^{*} p$ value $<0.01, \Delta p$ value $\leq 0.01$

their excretion to bile, urine or feces. Altered rates of metabolism can influence the systemic availability and residence time of xenobiotics, and hence affect xenobiotic toxicity or therapeutic effect. It is well established that certain xenobiotics induce the expression of specific Phase I and II metabolizing enzymes (Catania et al. 2004; Bock et al. 2000; Cummings et al. 2002). Better understanding of simultaneous regulation of metabolism and disposition may help to prevent these undesirable effects. In this study, the effects of fulvestrant treatment on the phase II enzyme UGT1A4 and the MRP family of drug transporters in ER + MCF7 and HepG2 cells were examined.

The high sensitivity of MCF7 and HepG2 cells towards fulvestrant (Woode et al. 2012; Osborne et al. 2004; Wakeling and Bowler 1987; Hu et al. 1993; Catania et al. 2004) limits time in in vitro experiments at higher doses.
In order to perform experiments at the highest effective dose for extended times, cells were pre-treated with $1 \mathrm{nM}$ fulvestrant for 30 days. This allowed for the experimental conditions used in this paper. Concentration and time experiments showed that treatment with $10 \mathrm{nM}$ fulvestrant for 48 hours significantly increased UGT1A4 expression in both cell lines.

Up regulation of UGT1A4 mRNA correlates with UGT1A4 protein expression, demonstrating that UGT1A4 protein expression is regulated at least partially by transcription. In previous studies, human liver microsomes with higher expression of UGT1A4 exhibited increased glucuronidation of anastrozole (Edavana et al. 2013). To determine if fulvestrant-induced increases of UGT1A4 expression had a similar effect in MCF7 and HepG2 cell lines, anastrozole glucuronidation assays were performed after fulvestrant treatment to simulate co-treatment. UGT1A4 expression

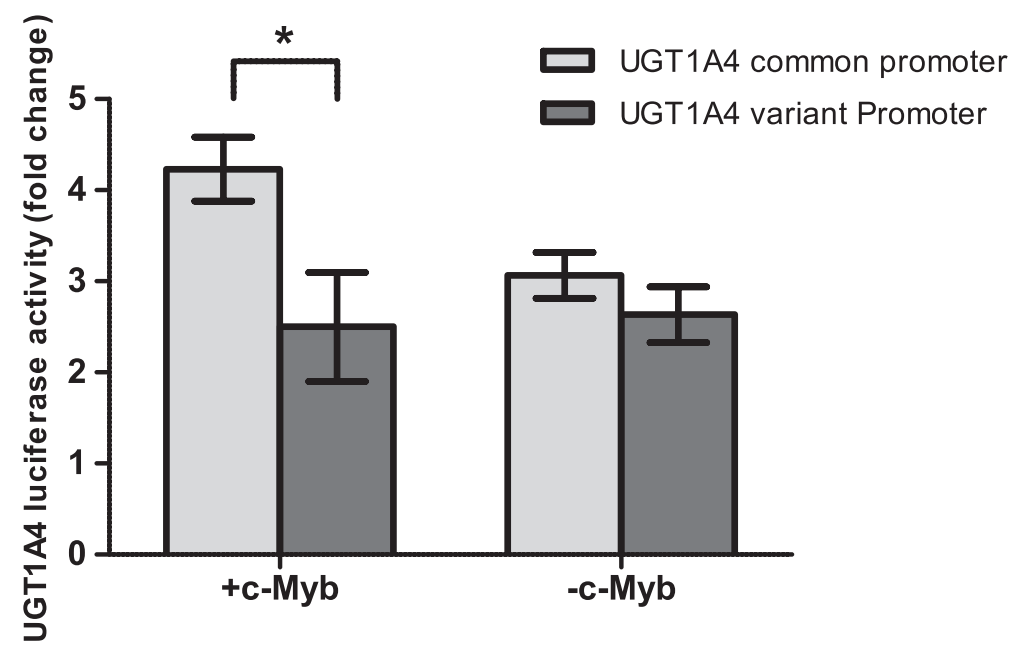

Figure 5 Luciferase activity in MCF7 cells +/- c-Myb transfected with UGT1A4 common or variant promoters. Cells were transfected either with UGT1A4 promoter constructs containing all common alleles or UGT1A4 promoter constructs containing all variant alleles in locations $-163,-217$ and -219 . Cells were treated with $10 \mathrm{mM}$ fulvestrant and luciferase activity was measured, and is displayed as fold-change ${ }^{*} \mathrm{p}$ value $=0.01$. 
correlated with anastrozole glucuronidation, indicating that up regulation of UGT1A4 by fulvestrant has an effect on co administration of drugs that are substrates of UGT1A4.

The increase in UGT1A4 upon fulvestrant treatment is thought to be mediated through the ER $\alpha$ pathway. When ER $\alpha$ was silenced in MCF7 and HepG2 cell lines, fulvestrant treatment no longer up regulated UGT1A4 expression, confirming that the ER $\alpha$ pathway has a role in UGT1A4 up regulation. There is no correlation between UGT1A4 expression and activity with ER $\alpha$ protein levels; however, there is correlation with ER $\alpha$ mRNA, indicating that there are other mechanisms or pathways co-regulating UGT1A4 expression upon fulvestrant treatment.

UGT1A4 promoter SNPs may also play a role in fulvestrant-induced UGT1A4 up regulation. Glucuronidation activities in different human tissues have been shown to exhibit a high degree of variation (Edavana et al. 2013; Shipkova et al. 2001; Strassburg et al. 2000). One explanation is the presence of SNPs within the coding regions of UGT1A4 genes that may lead to quantitative or qualitative alterations of specific catalytic activities (Ehmer et al. 2004; Edavana et al. 2013). Previous studies have revealed 3 SNPs located upstream of the ATG codon at $-163,-217$, and -219 (Edavana et al. 2013; Saeki et al. 2005; Erichsen et al. 2008; Benoit-Biancamano et al. 2009). In this study, reporter gene experiments show that UGT1A4 transcription after fulvestrant treatment is significantly reduced with either the $-163 \mathrm{~A}$ or the $-219 \mathrm{~T}$ variant genotype compared to those with the common $-163 G$ or $-219 \mathrm{C}$ genotype in MCF7 and HepG2 cell lines. In HepG2 cells, there was also a statistically significant increase in UGT1A4 expression with the -217G variant genotype. The genotype with all common alleles (-163G, $-217 \mathrm{~T}$ and $-219 \mathrm{C})$ appears to sustain full activity of the UGT1A4 gene promoter fragment, but the genotype with variant alleles reduced the activity by $40-60 \%$ in both cells lines. Combined, these data demonstrate that small variations in the UGT1A4 gene promoter region alter constitutive expression of UGT1A4 upon fulvestrant treatment. These findings may be relevant for coadministration of drugs that areUGT1A4 substrates such as tamoxifen, anastrozole, clozapine and lamotrigine. Genetic variants leading to constitutive expression and that alter the ability to respond to physiological inducers contribute to inter-individual variability in glucuronidation capacity. Therefore, pharmacogenetic risk associated with these variants should be considered in clinical studies.

Another factor related to the up regulation of UGT1A4 by fulvestrant treatment could be through changes in the binding capacity of transcription factors due to the presence of promoter SNPs in UGT1A4 (Quintana et al. 2011). In silico analysis with the is-rSNP program revealed that the $-163 \mathrm{~A}$ variant is associated with changes in the $c-M y b$ transcription factor binding site (Quintana et al. 2011). $\mathrm{c}-\mathrm{Myb}$ is an oncogene that is up regulated in breast cancer cells, and has been associated with estrogen response in breast cancer. Silencing $c-M y b$ in MCF7 cell lines $(c-M y b$ is not expressed in HepG2 cells) reduced fulvestrant induced luciferase activity of the promoter with all common alleles by 1.5 fold. There was no change in fulvestrant induced luciferase expression in the promoter with all variant alleles. This is the first time that $\mathrm{c}-\mathrm{Myb}$ has been reported to have a regulatory effect on the phase II metabolizing gene UGT1A4.

Interplay between transporters and drug-metabolizing enzymes has been postulated to have a major role in determining a drug's absorption and disposition (Wacher et al. 1995; Custodio et al. 2008; Pang et al. 2009). Phase II enzymes are localized with their transport systems, and both are induced by the same compounds, suggesting a correlated action (Bock et al. 2000). The transporter genes $M R P 1, M R P 2$, and $M R P 3$ are expressed in MCF7 cells, but only MRP2 and MRP3 are expressed in HepG2 cells (Ros et al. 2003). This study demonstrated that fulvestrant-induced UGT1A4 expression correlated with increased expression of MRP1 in MCF7 cells, and of $M R P 2$ and MRP3 in MCF7 and HepG2 cells. The present study is the first report of $U G T 1 A 4$ and $M R P 1, M R P 2$ and $M R P 3$ being coordinately induced by fulvestrant.

\section{Conclusion}

This data suggest that the UGT1A4-inducing activity of fulvestrant is probably mediated by $E R \alpha, c-M y b$ and promoter SNPs. This data also demonstrates that transporter genes $M R P 1, M R P 2$ and $M R P 3$ are also induced by fulvestrant, suggesting they may play a role in drug disposition in co-treatments. The clinical application of pharmacogenomics in cancer treatment will therefore require more detailed information concerning the functional effects of genetic variants in drug metabolizing enzymes and drug transporters.

\section{Abbreviations}

ER: Estrogen receptor; MRPs: Multidrug resistance-associated proteins; UGT1A4: UDP glucuronosyltransferase 1A4; GSTs: Glutathione S-Transferases; SULTs: Sulfotransferases; SERMs: Selective estrogen receptor modulators; UDPGA: UDP glucuronic acid; TED: Tris-EDTA-diethyldithiocarbamic; PWM: Position weight matrix.

\section{Competing interests}

The author(s) declare that they have no competing interests.

\section{Authors' contributions}

VKE contributed substantially to conception and design, conducted experiments, participated in data analysis and drafting the manuscript. RBP participated in conducting experiments, data analysis and drafting the manuscript. AYB participated in conducting experiments, data analysis and drafting the manuscript. SW participated in conducting experiments and drafting the manuscript. LR participated in conducting experiments and drafting the manuscript. IBD contributed to the statistical analysis and drafting the manuscript. SK contributed substantially to conception and 
design, and participated in data analysis and drafting the manuscript. All authors read and approved the final manuscript.

\section{Acknowledgements}

R01 CA1 18981, Pharmacogenetics of Hormonal Therapy for Breast cancer.

\section{Author details}

${ }^{1}$ Division of Medical Genetics, College of Medicine, University of Arkansas for Medical Sciences, 4301 W. Markham, \#580, Little Rock, AR, 72205, USA. ${ }^{2}$ Department of Environmental and Occupational Health, College of Public Health, Little Rock, AR, 72205, USA.

\section{Received: 29 October 2013 Accepted: 30 October 2013} Published: 20 November 2013

\section{References}

AstraZeneca (2012) AstraZeneca begins a new global study of FASLODEX ${ }^{\odot}$ (fulvestrant) injection in patients with hormone receptor-positive advanced breast cancer. Retrieved from http://www.astrazeneca-us.com/media/pressreleases/Article/20121029-astrazeneca-begins-a-new-global-study-of-faslodex

Benoit-Biancamano MO, Adam JP, Bernard O, Court MH, Leblanc MH, Caron P, Guillemette C (2009) A pharmacogenetics study of the human glucuronosyltransferase UGT1A4. Pharmacogenet Genomics 19(12):945-954. doi:10.1097/FPC.0b013e3283331637

Bock KW, Eckle T, Ouzzine M, Fournel-Gigleux S (2000) Coordinate induction by antioxidants of UDP-glucuronosyltransferase UGT1A6 and the apical conjugate export pump MRP2 (multidrug resistance protein 2) in Caco-2 cells. Biochem Pharmacol 59(5):467-470

Catania VA, Sanchez Pozzi EJ, Luquita MG, Ruiz ML, Villanueva SS, Jones B, Mottino AD (2004) Co-regulation of expression of phase II metabolizing enzymes and multidrug resistance-associated protein 2. Annals Hepatol 3(1):11-17

Chouinard S, Tessier M, Vernouillet G, Gauthier S, Labrie F, Barbier O, Belanger A (2006) Inactivation of the pure antiestrogen fulvestrant and other synthetic estrogen molecules by UDP-glucuronosyltransferase 1A enzymes expressed in breast tissue. Mol Pharmacol 69(3):908-920. doi:10.1124/mol.105.015891

Cui Y, Konig J, Buchholz JK, Spring H, Leier I, Keppler D (1999) Drug resistance and ATP-dependent conjugate transport mediated by the apical multidrug resistance protein, MRP2, permanently expressed in human and canine cells. Mol Pharmacol 55(5):929-937

Cummings J, Boyd G, Ethell BT, Macpherson JS, Burchell B, Smyth JF, Jodrell DI (2002) Enhanced clearance of topoisomerase I inhibitors from human colon cancer cells by glucuronidation. Biochem Pharmacol 63(4):607-613

Custodio JM, Wu CY, Benet LZ (2008) Predicting drug disposition, absorption/ elimination/transporter interplay and the role of food on drug absorption. Adv Drug Deliv Rev 60(6):717-733. doi:10.1016/j.addr.2007.08.043

Edavana VK, Dhakal IB, Williams S, Penney R, Boysen G, Yao-Borengasser A, Kadlubar S (2013) Potential role of UGT1A4 promoter SNPs in anastrozole pharmacogenomics. Drug Metab Dispos 41(4):870-877. doi: 10.1124/dmd.112.048157

Ehmer U, Vogel A, Schutte JK, Krone B, Manns MP, Strassburg CP (2004) Variation of hepatic glucuronidation: Novel functional polymorphisms of the UDPglucuronosyltransferase UGT1A4. Hepatology 39(4):970-977. doi:10.1002/hep.20131

Erichsen TJ, Ehmer U, Kalthoff S, Lankisch TO, Muller TM, Munzel PA, Manns MP, Strassburg CP (2008) Genetic variability of aryl hydrocarbon receptor (AhR)mediated regulation of the human UDP glucuronosyltransferase (UGT) 1A4 gene. Toxicol Appl Pharmacol 230(2):252-260. doi:10.1016/j.taap.2008.02.020

Group SO (2004) Anastrozole with or without fulvestrant as first-line therapy in postmenopausal women with metastatic breast cancer. Retrieved from: http://clinicaltrials.gov/show/NCT00075764

Hiscox S, Davies EL, Barrett-Lee P (2009) Aromatase inhibitors in breast cancer. Maturitas 63(4):275-279. doi:10.1016/.jmaturitas.2009.05.008

Howell A, Osborne CK, Morris C, Wakeling AE (2000) ICI 182,780 (Faslodex): development of a novel, "pure" antiestrogen. Cancer 89(4):817-825

Howell A, Robertson JF, Quaresma Albano J, Aschermannova A, Mauriac L, Kleeberg UR, Vergote I, Erikstein B, Webster A, Morris C (2002) Fulvestrant, formerly ICI 182,780, is as effective as anastrozole in postmenopausal women with advanced breast cancer progressing after prior endocrine treatment. J Clin Oncol 20(16):3396-3403
Hu XF, Veroni M, De Luise M, Wakeling A, Sutherland R, Watts CK, Zalcberg JR (1993) Circumvention of tamoxifen resistance by the pure anti-estrogen ICl 182,780. Int J Cancer J Int du Cancer 55(5):873-876

Kamdem LK, Liu Y, Stearns V, Kadlubar SA, Ramirez J, Jeter S, Shahverdi K, Ward BA, Ogburn E, Ratain MJ, Flockhart DA, Desta Z (2010) In vitro and in vivo oxidative metabolism and glucuronidation of anastrozole. $\mathrm{Br} J \mathrm{Clin}$ Pharmacol 70(6):854-869. doi:10.1111/j.1365-2125.2010.03791.x

Keppler D, Leier I, Jedlitschky G (1997) Transport of glutathione conjugates and glucuronides by the multidrug resistance proteins MRP1 and MRP2. Biologic Chem 378(8):787-791

Macintyre G, Bailey J, Haviv I, Kowalczyk A (2010) is-rSNP: a novel technique for in silico regulatory SNP detection. Bioinformatics 26(18):i524-i530. doi:10.1093/ bioinformatics/bta378

Morris C, Wakeling A (2002) Fulvestrant ('Faslodex')-a new treatment option for patients progressing on prior endocrine therapy. Endocr Relat Cancer 9(4):267-276

Muller-Decker K, Scholz K, Marks F, Furstenberger G (1995) Differential expression of prostaglandin $\mathrm{H}$ synthase isozymes during multistage carcinogenesis in mouse epidermis. Mol Carcinog 12(1):31-41

Munzel PA, Schmohl S, Heel H, Kalberer K, Bock-Hennig BS, Bock KW (1999) Induction of human UDP glucuronosyltransferases (UGT1A6, UGT1A9, and UGT2B7) by t-butylhydroquinone and 2,3,7,8-tetrachlorodibenzo-p-dioxin in Caco-2 cells. Drug Metab Dispos 27(5):569-573

Osborne CK, Pippen J, Jones SE, Parker LM, Ellis M, Come S, Gertler SZ, May JT, Burton G, Dimery I, Webster A, Morris C, Elledge R, Buzdar A (2002) Doubleblind, randomized trial comparing the efficacy and tolerability of fulvestrant versus anastrozole in postmenopausal women with advanced breast cancer progressing on prior endocrine therapy: results of a North American trial. J Clin Oncol 20(16):3386-3395

Osborne CK, Wakeling A, Nicholson RI (2004) Fulvestrant: an oestrogen receptor antagonist with a novel mechanism of action. Br J Cancer 90(Suppl 1):S2-S6. doi:10.1038/sj.bjc.6601629

Pang KS, Maeng HJ, Fan J (2009) Interplay of transporters and enzymes in drug and metabolite processing. Mol Pharm 6(6):1734-1755. doi:10.1021/ mp900258z

Quintana AM, Liu F, O'Rourke JP, Ness SA (2011) Identification and regulation of c-Myb target genes in MCF-7 cells. BMC cancer 11:30. doi:10.1186/1471-2407$11-30$

Robertson JF, Nicholson RI, Bundred NJ, Anderson E, Rayter Z, Dowsett M, Fox JN, Gee JM, Webster A, Wakeling AE, Morris C, Dixon M (2001) Comparison of the short-term biological effects of 7alpha-[9-(4,4,5,5,5-pentafluoropentylsulfinyl)-nonyl]estra-1,3,5, (10)-triene-3,17beta-diol (Faslodex) versus tamoxifen in postmenopausal women with primary breast cancer. Cancer Res 61(18):6739-6746

Robertson JF, Erikstein B, Osborne KC, Pippen J, Come SE, Parker LM, Gertler S, Harrison MP, Clarke DA (2004) Pharmacokinetic profile of intramuscular fulvestrant in advanced breast cancer. Clin Pharmacokinet 43(8):529-538

Ros JE, Libbrecht L, Geuken M, Jansen PL, Roskams TA (2003) High expression of MDR1, MRP1, and MRP3 in the hepatic progenitor cell compartment and hepatocytes in severe human liver disease. J Pathol 200(5):553-560. doi:10.1002/path.1379

Saeki M, Saito Y, Jinno H, Sai K, Hachisuka A, Kaniwa N, Ozawa S, Kawamoto M, Kamatani N, Shirao K, Minami H, Ohtsu A, Yoshida T, Saijo N, Komamura K, Kotake T, Morishita H, Kamakura S, Kitakaze M, Tomoike H, Sawada J (2005) Genetic variations and haplotypes of UGT1A4 in a Japanese population. Drug Metab Pharmacokinet 20(2):144-151

Schmittgen TD, Livak KJ (2008) Analyzing real-time PCR data by the comparative C(T) method. Nat Protoc 3(6):1101-1108

Shipkova M, Strassburg CP, Braun F, Streit F, Grone HJ, Armstrong WW, Tukey RH, Oellerich M, Wieland E (2001) Glucuronide and glucoside conjugation of mycophenolic acid by human liver, kidney and intestinal microsomes. Br J Pharmacol 132(5):1027-1034. doi:10.1038/sj.bjp.0703898

Sirois J, Simmons DL, Richards JS (1992) Hormonal regulation of messenger ribonucleic acid encoding a novel isoform of prostaglandin endoperoxide $\mathrm{H}$ synthase in rat preovulatory follicles. Induction in vivo and in vitro. J Biol Chem 267(16):11586-11592

Starlard-Davenport A, Lyn-Cook B, Beland FA, Pogribny IP (2010) The role of UDP-glucuronosyltransferases and drug transporters in breast cancer drug resistance. Exp Oncol 32(3):172-180

Strassburg CP, Kneip S, Topp J, Obermayer-Straub P, Barut A, Tukey RH, Manns MP (2000) Polymorphic gene regulation and interindividual variation of UDP- 
glucuronosyltransferase activity in human small intestine. J Biol Chem 275(46):36164-36171. doi:10.1074/jbc.M002180200

Wacher VJ, Wu CY, Benet LZ (1995) Overlapping substrate specificities and tissue distribution of cytochrome P450 3A and P-glycoprotein: implications for drug delivery and activity in cancer chemotherapy. Mol Carcinog 13(3):129-134

Wakeling AE, Bowler J (1987) Steroidal pure antioestrogens. J Endocrinol 112(3):R7-R10

Walton TJ, Li G, McCulloch TA, Seth R, Powe DG, Bishop MC, Rees RC (2009)

Quantitative RT-PCR analysis of estrogen receptor gene expression in laser microdissected prostate cancer tissue. Prostate 69(8):810-819. doi:10.1002/ pros.20929

Woode DR, Aiyer HS, Sie N, Zwart AL, Li L, Seeram NP, Clarke R (2012) Effect of berry extracts and bioactive compounds on fulvestrant (ICI 182,780) sensitive and resistant cell lines. Int J Breast Cancer 2012:147828. doi:10.1155/2012/ 147828

doi:10.1186/2193-1801-2-620

Cite this article as: Edavana et al:: Fulvestrant up regulates UGT1A4 and $M R P s$ through ERa and c-Myb pathways: a possible primary drug disposition mechanism. SpringerPlus 2013 2:620.

\section{Submit your manuscript to a SpringerOpen ${ }^{\circ}$ journal and benefit from:}

- Convenient online submission

- Rigorous peer review

- Immediate publication on acceptance

- Open access: articles freely available online

- High visibility within the field

- Retaining the copyright to your article 